\title{
Impact of Feeding Yeast Culture on Milk Yield, Milk Components, and Blood Components in Algerian Dairy Herds
}

\section{Ayad MA ${ }^{1 *}$, Benallou $\mathrm{B}^{1}$, Saim MS ${ }^{1}$, Smadi $\mathrm{MA}^{2}$ and Meziane $\mathrm{T}^{2}$}

${ }^{1}$ Ibn Khaldoun University, Veterinary Institute-14000, Tiaret, Algeria

${ }^{2}$ Hadj Lakhdar University, Veterinary Institute-05000, Batna, Algeria

\begin{abstract}
The main objective of this study was to estimate the effect of supplementation with Saccharomyces cerevisiae (BIOSAF ${ }^{\circledR}$ SC 47), on body condition score, milk production and some biochemical parameters in peripartum dairy cows. The experiment was conducted during 14 days before parturition to 45 days postpartum ( 20 milking). Holstein cows (16 primiparous and 4 multiparous) were randomly divided into two groups $(n=10)$; the groups were fed with same diet: One group received, Saccharomyces cerevisiae. Milk production and blood samples were taken. Body condition scores (BCS) were recorded. For statistical analysis, Minitab ${ }^{\circledR}$ 15.1.30.0.Fransh (๑ 2007 Minitab Inc) software was used. Addition of yeast culture to the diet ration was significantly increased. The average milk production per cow between the groups in all the experiment (by about $+25 \%$, i.e. $4.8 \mathrm{l} / \mathrm{day} / \mathrm{cow}$ ), with a positive effect in milk fat content and stabilization of the BCS, with reduction of reserve mobilization after calving. Moreover, this treatment has also induced systemic biochemical changes: increase of plasmatic total protein and albumin, whereas triglyceride and creatinine concentrations were significantly lowered, and cholesterol concentrations slightly reduced. The addition of yeast culture in the diet of Holstein cows was beneficial in improving milk production and milk fat, and some biochemical parameters.
\end{abstract}

Keywords: Supplementation; Probiotic; Milking cow; Peripartum; Biochemical parameters

\section{Introduction}

In Algeria, dairy cattle farming are characterized by the use of Holstein as principal breed. Forage availability and nutritive quality are frequently lacking. Breeders are then forced to distribute high quantity of concentrate, especially for milking dairy cows.

Based on a growing concern over the use of antibiotics and other growth promoters in the animal feed industry, interest in the effects of microbial feed additives on animal performance has increased. Supplementation with yeast culture has been used for over six decades.

Yeast (Saccharomyces cerevisiae) addition in this condition was reported to increase nutritional value of poor quality forages and high grain diets [1]. Newbold et al. [2] Beauchemin et al. [3] reported that yeast addition improves the development of rumen lactate-consuming bacteria; prevent accumulation of lactate, and rumen $\mathrm{pH}$ drops. Yeast is also observed to stimulate cellulolytic bacteria in the rumen, increase fiber digestion and flow of microbial protein from the rumen $[2,4]$. Moreover, yeast was reported by great number of studies to improve feed intake and milk yield in dairy cows. In addition, Arambel and Kent [1], Huber [5], Schingoethe et al. [6] suggested that yeast is more effective when animals are under stress, particularly heat stress. The objective of this study was to evaluate the effects of adding yeast culture feeding to lactating dairy cows, on their performance in peripartum.

\section{Materials and Methods}

\section{Cows and feeding}

The experiment was carried out between May 2010 and September 2010 in a private house farm in the area of Tiaret (West Algeria), with an average of 70 milking Holstein Friesian cows. The 20 late pregnant cows (16 primiparious and 4 multiparous) were randomly divided into two groups before calving, according to age, parity, body condition score and previous milk production. They were housed in separate rows on the farm and had free access to water. All cows calved during a two month period. The control group received a ration composed of forages and commercially available concentrate, as is indicated in figure 1.

Twenty grams of SC ( $n c y c s c 47$, biosaf heat resistant concentrate of live yeast) (lesafre, feed additives, France) were hand-mixed with a small amount of concentrate and were fed daily to each cow from the experimental group, before morning feeding, starting from two weeks before the expected calving date, until 45 days after parturition. Concentrate was composed of maize, soya bean meal, bran and mineral-

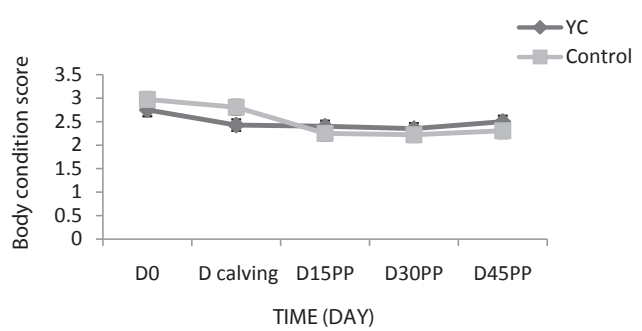

Figure 1: Mean body condition score in Saccaromyces cerevisiae and control group.

Mean ( \pm SEM) body condition score during 14 days before parturition and 45 days postpartum (measured every 2 week) in cows from the Saccharomyces cerevisiae group and control group $(n=10)$.

*Corresponding author: Ayad MA, Ibn Khaldoun University, Veterinary Institute-14000, Tiaret, Algeria, E-mail: aminevt@yahoo.fr

Received January 23, 2013; Accepted February 19, 2013; Published February 21, 2013

Citation: Ayad MA, Benallou B, Saim MS, Smadi MA, Meziane T (2013) Impact of Feeding Yeast Culture on Milk Yield, Milk Components, and Blood Components in Algerian Dairy Herds. J Veterinar Sci Technol 4: 135. doi:10.4172/21577579.1000135

Copyright: ( 2013 Ayad MA, et al. This is an open-access article distributed unde the terms of the Creative Commons Attribution License, which permits unrestricted use, distribution, and reproduction in any medium, provided the original author and source are credited. 
Citation: Ayad MA, Benallou B, Saim MS, Smadi MA, Meziane T (2013) Impact of Feeding Yeast Culture on Milk Yield, Milk Components, and Blood Components in Algerian Dairy Herds. J Veterinar Sci Technol 4: 135. doi:10.4172/2157-7579.1000135

Page 2 of 5

vitamin supplement. Proportion of concentrate in the ration (on dry matter basis) was higher than $50 \%$ and equal to $63 \%$. Forages were distributed ad libitum, and the concentrate quantity varied according to the milk yield (between 10 and $12 \mathrm{~kg}$ per day). They were milked daily at $4 \mathrm{~h} 30$ and $16 \mathrm{~h} 00$ (Table 1 ).

\section{Milk production data and body condition score}

During the experiment, cow identification number, date of calving, daily milk yield and disease occurrence data were recorded. Cows were milked twice a day. Milk production was recorded and sampled individually, daily starting in 7 day after parturition.

Milk samples for early lactation were stored at $4^{\circ} \mathrm{C}$ and sent to the laboratory of "la laiterie de SIDI-KHALED-Tiaret" (GIPLAIT), for milk fat every second week, until 7 weeks after parturition. Body condition scores (BCS) were recorded once per week from 14 day before calving, until 45 day PP, using a 5-point scale (1=thin and 5=fat), as described by Edmondson.

\section{Plasma metabolites}

Jugular blood vessel samples for biochemical analysis were collected in heparinized Venoject glass tubes (improvacuter, evacuated blood collection tube for in vitro diagnostic use) during day 0 (starting experiment), day of calving, day 15 PP, day 30 PP and day 45 PP.

After immediate centrifugation (10 min at $3500 \times \mathrm{g}$ ), approximately $5 \mathrm{ml}$ of plasma was removed and stored at $-25^{\circ} \mathrm{C}$, until analysis. An automatic multiparameter analyzer for clinical chemistry (secomam) was used for enzymatic determination of plasma glucose, cholesterol, triglycerides, urea, albumin, total protein and creatinin, with commercially available kits (SPINREACT, SA, Spain).

\section{Statistical analysis}

The different results are described by the mean and standard deviation SD. The variance homogeneity between treatments was verified by the Bartlett test. The results were subjected to analysis of variance (ANOVA 1), to determine the effect of yeast supplementation

\begin{tabular}{|c|c|c|c|}
\hline composition & DM basis (\%) & UF/kg & MAD (g/kg) \\
\hline Maize & 68 & 0.748 & 40.8 \\
\hline bran & 10 & 0.073 & 10.7 \\
\hline Soya bean meal & 20 & 0.206 & 86.2 \\
\hline Phosphate & 1 & & \\
\hline C.M.V & 1 & & \\
\hline Total & 100 & 1.027 & 137.7 \\
\hline \multicolumn{2}{|l|}{ VitaminePP } & Calcium & $190000 \mathrm{mg}$ \\
\hline \multicolumn{2}{|l|}{ VitamineC } & Fer & $5000 \mathrm{mg}$ \\
\hline \multicolumn{2}{|r|}{$1300000 \mathrm{UI}$} & lode & $30 \mathrm{mg}$ \\
\hline \multicolumn{2}{|l|}{ VitamineD3 } & Cobalt & $10 \mathrm{mg}$ \\
\hline \multicolumn{2}{|l|}{ VitamineB2 } & cuivre & $1000 \mathrm{mg}$ \\
\hline \multicolumn{2}{|l|}{ VitamineB1 } & Manganèse & $25000 \mathrm{mg}$ \\
\hline VitamineB 12 & $0.5 \mathrm{mg}$ & Zinc & $5000 \mathrm{mg}$ \\
\hline VitamineE & $1250 \mathrm{mg}$ & Sélénium & $10 \mathrm{mg}$ \\
\hline PanthoTanatede Calcium & $200 \mathrm{mg}$ & Bétaine & $2500 \mathrm{mg}$ \\
\hline AcideNicotinique & $240 \mathrm{mg}$ & & \\
\hline ChlorurDecholine & $30000 \mathrm{mg}$ & & \\
\hline Vitaminek3 & $130 \mathrm{mg}$ & & \\
\hline Dimethionine & $2400 \mathrm{mg}$ & & \\
\hline
\end{tabular}

Composition of C.M.V/ Kg

Table 1: Composition and characteristics of concentrate (VLB20). on the parameters considered. The significance level chosen is at least $5 \%$. All these tests are conducted using the statistical software Minitab 15.1.30.0.Fransh (๔ 2007 Minitab Inc).

\section{Results}

\section{Milk production}

Supplementation with SC had statistically significant effect on milk production over the study period. Mean $( \pm$ SEM) daily milk yield was $32.7 \pm 1.39 \mathrm{~kg} / \mathrm{d}$ for the experimental group, and $30.7 \pm 5.3 \mathrm{~kg} / \mathrm{d}$ for the control group. The changes in milk yield over time are illustrated in figures 1-5. From 7 days PP, the milk yield in the two groups as in tables 2 and 3.

\section{Discussion}

In our test conditions, the complementation in Saccharomyces cerevisiae during the period from the last 2 weeks prepartum to 6 weeks post partum has a better effect on body condition score in postpartum cows. Similar results were reported by Dann et al. [7]. In addition, during the period of peak lactation (around the 5th week of

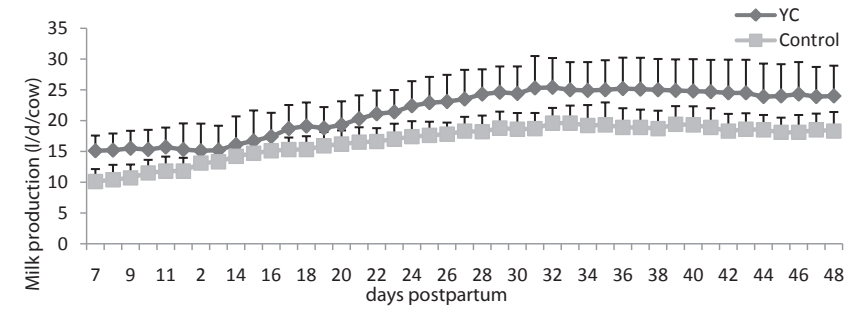

Figure 2: Mean of daily milk yield in Saccharomyces cerevisiae and contro group. Daily milk yield during the first 49 days.

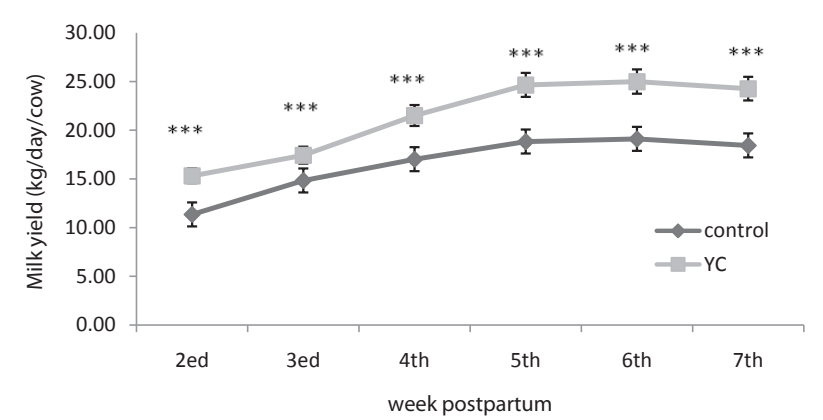

Figure 3: Evolution of milk production mean/week in cows from the Saccharomyces cerevisiae group and control group.

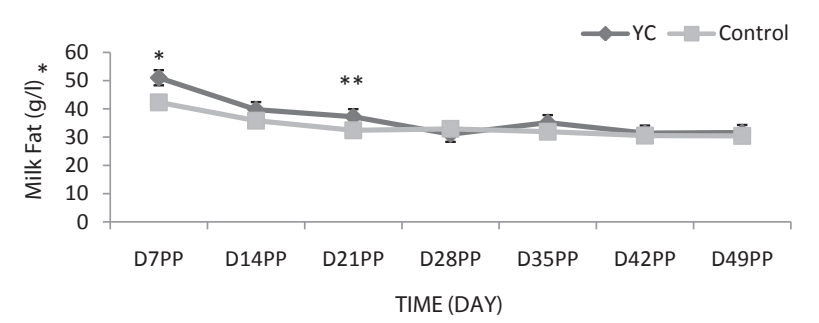

Figure 4: Mean daily milk fat production in Saccharomyces cerevisiae and control group. Mean ( \pm SEM) daily milk fat during the first 8 weeks from parturition (measured every second week) in cows from the Saccharomyces cerevisiae group and control group $(n=10)$. 
lactation), the stage where energy reserves are heavily used to support milk production, cows supplemented with yeast can maintain weight and body condition better than controls. While some authors find no significant improvements in body condition and body weight, after adding yeast to the diet of the cow peripartum [8,9], they recorded, however, decreased weight loss postpartum. These results reflect a lower mobilization of endogenous reserves of cows supplemented with yeast, perhaps suggesting a greater availability of energy. This surplus of available energy could be attributed to excessive consumption of

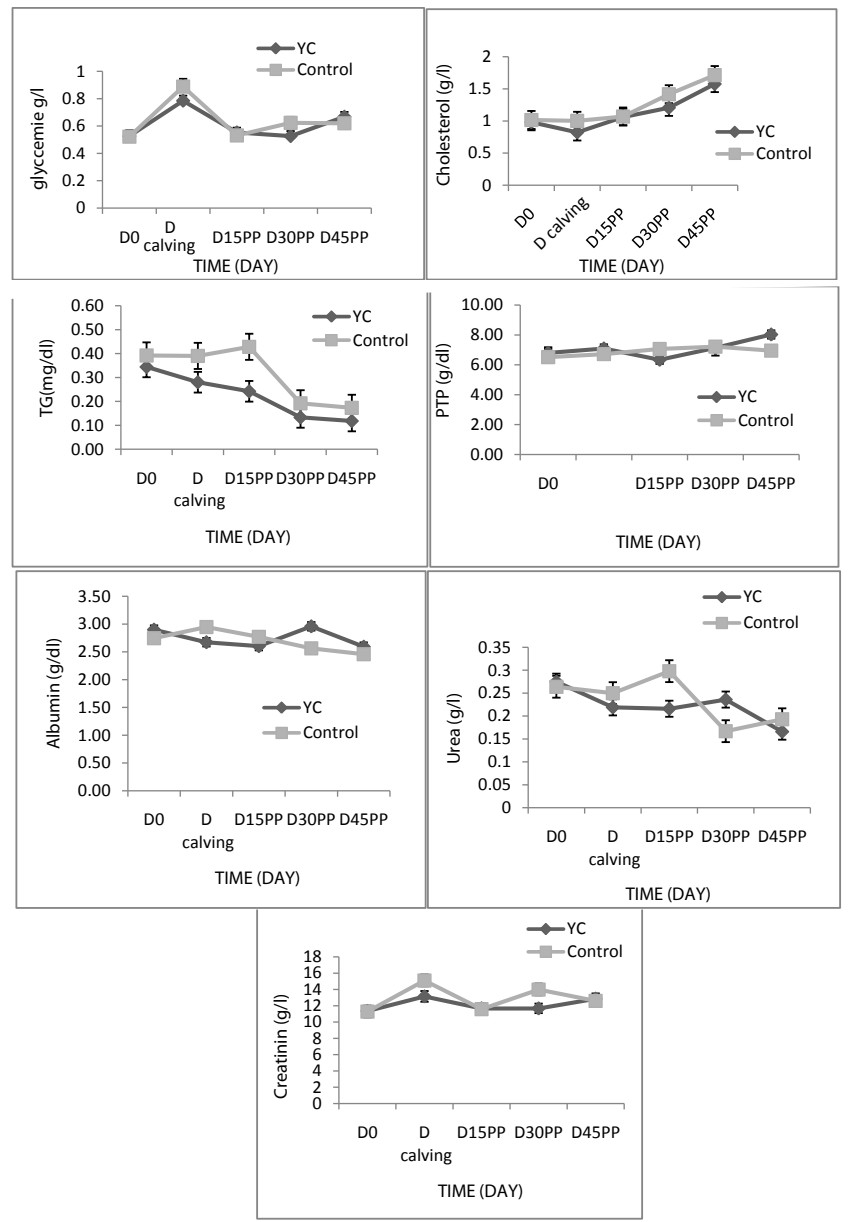

Figure 5: Effect of yeast culture $(Y C)$ on blood plasma components.

\begin{tabular}{|c|c|c|c|}
\hline BCS & Control $(n=10)$ & $Y C(n=10)$ & \pm SDP \\
\hline D0 & $2,97 \pm 0,24$ & $2,75 \pm 0.54$ & 0,247 \\
\hline (D calving) & $2,81 \pm 0,24$ & $2,43 \pm 0,66$ & 0,137 \\
\hline (D15PP) & $2,25 \pm 0,38$ & $2,40 \pm 0,56$ & 0,570 \\
\hline (D30PP) & $2,22 \pm 0,33$ & $2,35 \pm 0,39$ & 0,548 \\
\hline (D45PP) & $2,31 \pm 0,36$ & $2,50 \pm 0,28$ & 0,142 \\
\hline
\end{tabular}

Variation on BCS in peri et postpartum

\begin{tabular}{|l|l|l|}
\hline From D0 to D calving & -0.16 & -0.32 \\
\hline From D calving to D30PP & -0.59 & -0.08 \\
\hline From D30 to D45PP & +0.09 & +0.15 \\
\hline From D calving to D45PP & -0.50 & +0.07 \\
\hline
\end{tabular}

$\mathrm{SD}$ : standard deviation

Table 2: Effect of supplementation diet with Saccharomyces cerevisiae on body condition score.

\begin{tabular}{|c|c|c|c|}
\hline $\begin{array}{c}\text { PL mean per } \\
\text { week }(I / c o w)\end{array}$ & Control $(n=10)$ & $Y C(n=10)$ & $\pm S D P<$ \\
\hline $2^{\text {nd }}$ week & $11.34 \pm 2.30$ & $15.31 \pm 3.21$ & ${ }^{* * *}$ \\
\hline $3^{\text {rd }}$ week & $14.82 \pm 2.05$ & $17.42 \pm 4.15$ & ${ }^{* * *}$ \\
\hline $4^{\text {th }}$ week & $17.01 \pm 2.24$ & $20.50 \pm 3.98$ & ${ }^{* * *}$ \\
\hline $5^{\text {th }}$ week & $18.82 \pm 2.52$ & $23.64 \pm 4.40$ & ${ }^{* * *}$ \\
\hline $6^{\text {th }}$ week & $19.10 \pm 3.00$ & $23.98 \pm 4.75$ & ${ }^{* * *}$ \\
\hline $7^{\text {th }}$ week & $18.42 \pm 2.58$ & $23.25 \pm 4.99$ & ${ }^{* * *}$ \\
\hline
\end{tabular}

SD : standard deviation. ${ }^{* *}:$ p<0.001.

Table 3: Impact of supplementation yeast culture Saccharomyces cerevisiae on milk production measured between $2^{\text {ed }}$ and $7^{\text {th }}$ weeks for lactation.

dry matter intake, since the quantities of food distributed under our conditions were identical for both groups. It is rather associated with the complementation of the food in Saccharomyces cerevisiae.

Our study reveals a significant improvement in milk production, induced by the incorporation of Saccharomyces cerevisiae in the diet, as reported in previous studies [10-14]. In our testing, production of milk during the first 6 weeks of lactation rose $23 \%$ in cows supplemented with yeast probiotic, while other authors reported relatively lower responses ranging from $3-9 \%[7,8,11,13,15]$. Response to probiotics is often very different between studies because of the variability related to diets distributed, types and doses of yeast used, and the animals tested [10].

Moreover, it appears that the magnitude of improvement of milk production depends on the stage of lactation; it would be higher than in early or late lactation [16]. Analysis of the milk production curve shows that the peak of lactation of cows fed with Saccharomyces cerevisiae stretches longer than control cows ( 4 weeks vs 3 weeks, respectively). This positive effect of yeast on the persistence of peak lactation is also mentioned by Wohlt et al. [11] in cows and heifers by Wallace [17] in primiparous and multiparous cows.

In this test, the ration to all cows can theoretically cover the maintenance requirements, and production needs about 14.18 liters of milk/d. This ration was calculated based on average milk production of cattle, previously recorded. Our results show that supplemented cows produce more milk than controls. This relative increase in milk production is not due to overconsumption of dry matter intake, but linked to the complementation of Saccharomyces cerevisiae in the food, as reported by Newbold et al. [18]. Indeed, all cows in our trial has consumed the same amount of food (ingested equalized). It is rather associated with better recovery of the ration, allowed by the probiotic through interaction with the microbial flora. Probiotics stabilize rumen $\mathrm{pH}$ by competing with bacteria that produce lactate [3], providing nutrients (at death), and allowing the growth of bacteria by destroying the lactate [19]. This allows the maintenance of the cellulolytic flora and enhances the degradation of plant fibers, and therefore, the digestibility of the diet [18]. Furthermore, probiotics enhance the intestinal absorption of nutrients intake of vitamin B1 (thiamin), which promotes the colonization of plants by the rumen, and further improves the digestibility of the ration [15]. The recovery of nitrogen is also permitted by uptake of ammonia by probiotics, which are themselves then digested $[2,4,18]$. Several tests indicate that the increase in milk production induced by dietary supplementation with Saccharomyces cerevisiae, is not always associated with changes in protein and fat content of milk [19]. Nevertheless, an increase of fat in the milk of cows fed the probiotic yeast was reported by Piva et al. [13], Putnam et al. [14].

In our test, this increase in fat is seen at the second and third 
week ( $\mathrm{p}=0.045, \mathrm{p}=0.003$ ), respectively, of complementation in yeast. According to the literature, improvement of fat milk in dairy cows supplemented with yeast is associated with a positive effect of the stimulation of cellulolytic bacteria, and a preferred orientation of fermentation to acetic acid production, especially for diets rich in concentrate, or containing little forage degradable [13]. In this study, we explored the impact of the Saccharomyces cerevisiae supplementation on some blood biochemical parameters, namely glucose, TG, cholesterol, total protein, urea, albumin and creatinin. These parameters are often used to assess the nutritional status of the cow in transition [20-22]. Plasma glucose levels measured in this study ranged between 0.52 and $0.67 \mathrm{~g} / \mathrm{l}$. These values are mostly in the normal ranges of blood glucose in dairy cows reported in the literature $(0.40-0.75 \mathrm{~g} / \mathrm{l}),[23,24]$. Overall, plasma glucose levels measured during our study ranged between 0.52 and $0.66 \mathrm{~g} / \mathrm{l}$, except for results of samples found outside the threshold normal: 0.78 and $0.88 \mathrm{~g} / \mathrm{l}$ for batch baking and the control group, respectively. Blood glucose levels measured at parturition observed hyperglycemia in both groups supplemented and control: $0.78 v s .0 .88$, respectively, which justifies the sudden change from a ration less energy to high energy diets, without adjustment period. It was observed that the concentration of glucose in the control group is higher than that supplemented with probiotics.

It is interesting to note that the contribution of probiotic yeast seems to maintain a plasma level of glucose in the normal range. We also emphasize that in our experimental conditions, glucose cows being $S$. cerevisiae, has not changed compared to the control group, this negative effect of yeast on glucose is also reported by studies conducted in dairy cows [14], or calves [25], who have noticed no change in blood glucose after addition of yeast. Blood glucose was reduced in the same fistulated ram, about 39\% (NS), as reported by Iwanska et al. [26].

In other tests, the plasma glucose level of cows fed with yeast probiotic supplementation tends to be always higher than those observed in control cows $(+6 \%, \mathrm{p}=0.18$ : [13]; $15 \%, \mathrm{p}<0.05$ [9]. The mismatch of data could be linked to the nature of the ration distributed in nature, dose and duration of supplementation of yeast, and may be different, depending on the orientation of the metabolic productions (meat, milk). It is well established that plasma glucose is a sensitive measure of the energy balance in dairy cows [27], with a positive correlation between these parameters [22]. In our test conditions, blood glucose levels are stabilized in the normal values in the supplemented groups, but it is not in controls group.

In this experiment, plasma concentrations of total proteins are broadly distributed in the range of values considered normal in the literature (6.5-7.5 g/l) according to Lesmeister et al. [24]. With the exception of the values recorded at the end of the test (D45PP), or there was an increase in the protein content of batch supplemented with yeast $(+15 \%, p=0.10)$. This increase can be related to the $S$. cerevisiae. Many bibliographic data also show elevated plasma total protein, after supplementation of the ration in S. cerevisiae in dairy cows [26,27], and in rams [26]. Yeast probiotics stimulate microbial activity and increase the use of nitrogen by the rumen [18]. The efficiency of nitrogen use in ruminants supplemented food in yeast involve both an increase in the use of ammonia into microbial protein, an increased flow and absorption of acids, and also altered metabolism of endogenous nitrogen [15].

Nevertheless, some studies report that serum protein is not increased in calves supplemented with yeast [25].
In our test, serum albumin is between the usual values (2.3$3.6 \mathrm{~g} / \mathrm{l})$ [24], for supplemented and control group. The plasma level of albumin is very important, because it directly reflects the state of nitrogen ration of dairy cows, with liver function that synthesizes this protein among the different proteins found in the vascular torrent. The incorporation of yeast did not alter the plasma levels of albumin, with the exception of the values recorded on the 30th and 45th day postpartum, where we noticed an increase for the batch supplemented cons that observed in the control group of $(+15 \%, p=0.21$, and $5 \%$, $\mathrm{p}=0.46 \%)$.

In this experiment, plasma urea concentrations measured throughout the experimental period are broadly similar in the norms, and values considered normal in the literature $(0.2-0.3 \mathrm{~g} / \mathrm{l})$ [24]. In our experimental conditions, the incorporation of yeast in the diet did not affect plasma urea levels, with the exception of values measured at day $30 \mathrm{PP}$, or the difference between the batch supplemented and control animals was highly significant $(+41 \%, p<0.001)$. Many bibliographic data show an increase of uremia, after supplementation of the ration with $S$. cerevisiae in dairy cows $[26,27]$. Nevertheless, some studies report that uremia was even slightly reduced $(-12 \%$, NS) in dairy cows supplemented with yeast in mid-lactation [13]. Concentrations of excess ammonia in the rumen is unencumbered by the bacteria could induce high levels of uremia [27], quoted by Iwanska et al. [26]. The concentration of urea in the blood is intimately associated with the efficiency with which dietary protein is used, and suggests that plasma levels of ureic ammonia are an indicator of protein degradability in the rumen and protein intake post-rumen [27]

Moreover, under our experimental conditions, the results for plasma cholesterol in both experimental groups operate in the same way, except for values at or day $30 \mathrm{PP}$, day $45 \mathrm{PP}$, and we see high cholesterol in the control group1.41 $1.71 \mathrm{~g} / \mathrm{l}$, respectively. These values are outside the usual values quoted by Lesmeister et al. [24] (0.8-1.2 $\mathrm{g} / \mathrm{l})$, cholesterol values are lower for the batch supplemented compared to control group, but this difference is not statistically significant $(\mathrm{p}>0.05)$. The few studies available that have addressed this parameters indicate that cholesterol also varies little after complementation in yeast probiotic $[13,26]$.

In our study, supplementation in Saccharomyces cerevisiae induced a significant response and reduction of plasma triglyceride levels, compared with control cows. Differences were recorded between the two groups, going from $12-44 \%$, during the beginning of the trial $(\mathrm{p}=0.16)$ and 15 th day postpartum $(\mathrm{p}<0.01)$, respectively, come to the end of the experiment, with a range of $29 \%(p=0.21)$. Such a decrease was also noted by Iwanska et al. [26], in calves supplemented with yeast $(-57 \%$ versus controls, $\mathrm{p}<0.01)$. In addition, the decline of circulating triglycerides confirms recent information obtained in the mouse and chicken, where the addition of yeast to the food decreased serum levels of TG, phospholipids and the proportion of abdominal fat, quoted by Iwanska et al. [26]; however, the mechanisms of action involved in these variations are not yet known.

Finally, in this study, the serum creatinine obtained in both experimental groups is in the range of usual values quoted in the literature, and vary between 10 and $27 \mathrm{~g} / \mathrm{l}$, according to Lesmeister et al. [24]. We noticed a very significant difference $(p=0.002)$ between cows supplemented and those not supplemented with probiotics on the 30th day after parturition, with a higher value for the control group $16 \%$, compared to the cows supplemented. Due to lack of studies available to discuss this setting, we noticed an increase in creatinine with increased protein catabolism in control cows that is used as fuel 
Citation: Ayad MA, Benallou B, Saim MS, Smadi MA, Meziane T (2013) Impact of Feeding Yeast Culture on Milk Yield, Milk Components, and Blood Components in Algerian Dairy Herds. J Veterinar Sci Technol 4: 135. doi:10.4172/2157-7579.1000135

in gluconeogenesis (gluconeogenic amino acids), for the manufacture of glucose, knowing although this period coincides with peak lactation, where a supply of glucose is required for the production of lactose.

\section{Conclusion}

Our results confirm the advantage of incorporating the probiotic yeast, Saccharomyces cerevisiae, in the diet of the cows during the peripartum, to improve milk production, body condition and minimize the loss of weight around calving. These effects are related to changes in the metabolic profile identified in our terms. It seems necessary to explore the mechanisms of action of Saccharomyces cerevisiae on the metabolic activities and intra-ruminal lipid metabolism, and on nitrogen in peripartum dairy cows.

\section{References}

1. Arambel MJ, Kent BA (1990) Effect of yeast culture on nutrient digestibility and milk yield response in early- to midlactation dairy cows. J Dairy Sci 73: 15601563.

2. Newbold CJ, Wallace RJ, Mcintosh FM (1996) Mode of action of the yeast Saccharomyces cerevisiae as a feed additive for ruminants. Br J Nutr 76: 249261.

3. Beauchemin KA, Yang WZ, Morgavi DP, Ghorbani GR, Kautz W, et al. (2003) Effects of bacterial direct-fed microbials and yeast on site and extent of digestion, blood chemistry, and subclinical ruminal acidosis in feedlot cattle. $J$ Anim Sci 81: 1628-1640.

4. Jouany JP, Morgavi DP (2007) Use of 'natural' products as alternatives to antibiotic feed additives in ruminant production. Animal 1: 1443-1466.

5. Huber JT (1998) Yeast products help cattle handle heat. Hoard's Dairyman 143-367

6. Schingoethe DJ, Linke KN, Kalscheur KF, Hippen AR, Rennich DR, et al. (2004) Feed efficiency of mid-lactation dairy cows fed yeast culture during summer. $J$ Dairy Sci 87: 4178-4181.

7. Dann HM, Drackley JK, Mccoy GC, Hutjens MF, Garrett JE (2000) Effects of yeast culture (Saccharomyces cerevisiae) on prepartum intake and postpartum intake and milk production of jersey cows. J Dairy Sci 83: 123-127.

8. Robinson PH (1997) Effect of yeast culture (Saccharomyces cerevisiae) on adaptation of cows to diets postpartum. J Dairy Sci 80: 1119-1125.

9. Nocek JE, Kautzt WP (2006) Direct-fed microbial supplementation on rumina digestion, health, and performance of pre- and postpartum dairy cattle. J Dairy Sci 89: 260-266.

10. Williams PE, Tait CA, Innes GM, Newbold CJ (1991) Effects of the inclusion of yeast culture (saccharomyces cerevisiae plus growth medium) in the diet of dairy cows on milk yield and forage degradation and fermentation patterns in the rumen of steers. J Anim Sci 69: 3016-3026.

11. Wohlt JE, Finkelstein AD, Chung CH (1991) Yeast culture to improve intake, nutrient digestibility, and performance by dairy cattle during early lactation. $J$ Dairy Sci 74: 1395-1400.
12. Wohlt JE, Corcione TT, Zajac PK (1998) Effect of yeast on feed intake and performance of cows fed diets based on corn silage during early lactation. $J$ Dairy Sci 81: 1345-1352.

13. Piva G, Belladonna S, Fusconi G, Sicbaldi F (1993) Effects of yeast on dairy cow performance, ruminal fermentation, blood components, and milk manufacturing properties. J Dairy Sci 76: 2717-2722.

14. Putnam DE, Schwab CG, Socha MT, Whitehouse NL, Kierstead NA, et al. (1997) Effect of yeast culture in the diets of early lactation dairy cows on ruminal fermentation and passage of nitrogen fractions and amino acids to the small intestine. J Dairy Sci 80: 374-384

15. Erasmus LJ, Botha PM, Kisner A (1992) Effect of yeast culture supplement on production, rumen fermentation, and duodenal nitrogen flow in dairy cows. $J$ Dairy Sci 75: 3056-3065

16. Majdoub-Mathlouthi L, Kraiem K, Larbier M (2009) Effects of feeding Saccharomyces cerevisiae Sc 47 to dairy cows on milk yield and milk components, in Tunisian conditions. Livestock Research for Rural Development 21

17. Wallace RJ (1994) Ruminal microbiology, biotechnology, and ruminant nutrition: progress and problems. J Anim Sci 72: 2992-3003.

18. Newbold CJ, Mcintosh FM, Wallace RJ (1998) Changes in the microbial population of a rumen-simulating fermenter in response to yeast culture. Can J Anim Sci 78: 241-244.

19. Vandehaar MJ, Yousif G, Sharma BK, Herdt TH, Emery RS, et al. (1999) Effect of energy and protein density of prepartum diets on fat and protein metabolism of dairy cattle in the periparturient period. J Dairy Sci 82: 1282-1295.

20. Mohebbi-Fani, Nazifi M, Shekakforush S, Fathi SS (2005) Changes of protein fractions, lipoproteins, ceruloplasmin and urea nitrogen in serum of periparturient cows receiving dietary monensin. Rev Med Vet 156: 170-174

21. Reist M, Erdin D, von Euw D, Tschuemperlin K, Leuenberger $\mathrm{H}$, et al. (2002) Estimation of energy balance at the individual and herd level using blood and milk traits in high-yielding dairy cows. J Dairy Sci 85: 3314-3327.

22. Plet $\mathrm{J}$ (2007) Commemorative interest data, clinical and biochemical etiologic diagnosis and prognosis of peripartum metabolic diseases in cattle caused decubitus: Clinical study of 91 cases. 188

23. Brugere-Picoux J, Remy D (1995) Reduced availability of glucose. The dispatch technique, Technical Supplement 46. The Dispatch Veterinary 9-21.

24. Lesmeister KE, Heinrichs AJ, Gabler MT (2004) Effects of supplemental yeast (Saccharomyces cerevisiae) culture on rumen development, growth characteristics, and blood parameters in neonatal dairy calves. J Dairy Sci 87: 1832-1839.

25. Galip N (2006) Effect of supplemental yeast culture on ruminal protozoa and blood parameters in rams. Revue Med Vet 157: 519-524.

26. Iwanska S, Strusinska D, Zalewski W, Opalka A (1999) The effect of Saccharomyces cerevisiae 1026 used alone or with vitamin-mineral premix on milk yield and milk composition in dairy cows. Acta Vet Hung 47: 41-52.

27. Onifade AA, Babatunde GM (1996) Supplemental value of dried yeast in a highfibre diet for broiler chicks. Anim Feed Sci Technol 62: 91-96. 